\title{
Study on the catalysts of sulfur-odor gas pollution treatment
}

\author{
Fang Liu $\cdot$ Jinjin Lu $\cdot$ Chaocheng Zhao
}

Received: 19 May 2014/ Accepted: 19 June 2014/Published online: 6 July 2014

(C) The Author(s) 2014. This article is published with open access at Springerlink.com

\begin{abstract}
Aiming at the characteristics and current status of refineries' odor pollution, the sulfur containing odor gas-hydrogen sulfide was chosen as a typical object and treated by using the adsorption-catalytic oxidation method in the laboratory. This research focused on the preparation of adsorptive catalyst with high sulfur capacity at room temperature. The results showed that the sulfur capacity of walnut shell activated carbon (WSAC) was up to $351 \mathrm{mg} /$ $\mathrm{g}$, specific surface area was $2,030 \mathrm{~m}^{2} / \mathrm{g}$, and the pore volume of microspores was $0.608 \mathrm{~mL} / \mathrm{g}$. By comparison with the commercial activated carbon, it is found that the specific surface area, the sulfur capacity, and iodine value of WSAC have been improved significantly. The sulfur capacity of WSAC modified by $\mathrm{KIO}_{3}$ with mass fraction of $1 \%$ was up to $459 \mathrm{mg} / \mathrm{g}$.
\end{abstract}

Keywords Hydrogen sulfide - Walnut shell activated carbon $\cdot$ Modification $\cdot$ Desulfurization

\section{Introduction}

In recent years, with the industry development, especially the growing scale of petrochemical enterprise development, the odor emissions increase dramatically. The odor damage is very serious and has aroused the widespread interest. Because of the characteristics of the crude oil composition, the oil refining process produces a large amount of the sulfur containing odor substances. The sulfur containing odor substances can cause serious environment

F. Liu $(\bowtie) \cdot$ J. Lu $\cdot$ C. Zhao

College of Chemical Engineering, China University of Petroleum, Qingdao, China

e-mail: liufangfw@163.com pollution. In addition, with the increase of domestic crude oil quality deterioration and sulfur content and the imports of high-sulfur crude oil, the sulfur containing odor pollution becomes worse and has seriously affected the petrochemical enterprise's survival and development [1]. Therefore, the study on the sulfur containing odor treatment is imperative.

At present, the treatment methods of sulfur containing odor pollution mainly include physical method, chemical method, and biological method [2-5]. The above treatment methods can be used alone, but each of them has its advantages and disadvantages. Comparing with other methods, the adsorption method has the advantage of good effect and simple operation. But, it is mainly restricted by adsorbent adsorption performance and regeneration performance.

More than half of odorous pollutants are sulfur containing gas [6]. In these sulfur containing gas, hydrogen sulfide is the main odor gas. $\mathrm{H}_{2} \mathrm{~S}$ can be detected by most people as low as $0.0047 \mathrm{mg} / \mathrm{m}^{3}$ [7]. From the point of a purification system engineering design, the odor threshold of $\mathrm{H}_{2} \mathrm{~S}$ is $0.18 \mathrm{mg} / \mathrm{m}^{3}$ [8]. Hydrogen sulfide not only can cause a certain degree of corrosion to equipment and line, but also has the serious threat to personal safety. It is also one of the atmospheric pollutants urgently needed to be treated [9]. So, different types of desulfurization catalyst get more attention to eliminate $\mathrm{H}_{2} \mathrm{~S}$ pollution. Previous studies showed that the activated alumina was mostly chosen as the carrier. The metal oxide or a small amount of precious metals could be loaded on the activated alumina to make the supported catalysts [10-12]. Activated carbon has large surface area, huge pore volume, and complex pore structure. So, it can fulfill a dual role as a catalyst for the direct oxidation of hydrogen sulfide to sulfur and as an adsorbent for removing sulfur and its oxides from the gas stream. The selectivity of activated carbon for oxidation of 
$\mathrm{H}_{2} \mathrm{~S}$ to sulfur is dependent on process conditions, textural characteristics, structural characteristics, and surface chemical characteristics of the carbon catalysts [13, 14].

Considering the cost and treatment effect, this article used the walnut shell waste as raw material and adopted $\mathrm{ZnCl}_{2}$ activation method to prepare the high-specific surface area activated carbon. The preparation conditions of activated carbon were investigated and optimized. The walnut shell activated carbon (WSAC) was also modified and characterized.

\section{Materials and methods}

\section{Experimental facility}

The experimental apparatus included gas generator, gas distribution device, and adsorption device. In the gas generator, sodium sulfide solution and sulfuric acid were used to prepare the hydrogen sulfide gas. The gas generating speed was controlled by adjusting the drip speed of tow solutions.

Hydrogen sulfide gas was mixed with air in the secondary distribution device and then entered into the adsorption device. The adsorption device was controlled by the constant-temperature water bath. The sulfur capacity of activated carbon was calculated by measuring the concentration of import and export hydrogen sulfide gas and the adsorption time. The experimental device is shown in Fig. 1.

\section{Preparation of WSAC}

The walnut shells were crushed, removed impurities by a magnet, washed, dried, and sized. The prepared walnut shells were stored in the jar. The $\mathrm{ZnCl}_{2}$ solution was prepared in a certain mass fraction. $300 \mathrm{~g}$ prepared walnut shells were added into the $\mathrm{ZnCl}_{2}$ solution, stirred, and allowed to separate for $24 \mathrm{~h}$. After drying, the sample was put into the tube furnace and carbonized at $300{ }^{\circ} \mathrm{C}$ under nitrogen atmosphere. The prepared carbonization sample was steeped in the $\mathrm{ZnCl}_{2}$ solution for $20 \mathrm{~min}$. After extracting and drying, the carbonization sample was put into the muffle furnace. And then, the sample was cooled and boiled with hydrochloric acid for $20 \mathrm{~min}$. The product was washed with deionized water to neutral and put into the oven at $120{ }^{\circ} \mathrm{C}$.

\section{Desulfurization performance of WSAC}

The $10 \mathrm{~g}$ WSAC was put into the glass adsorption tube (25 $\mathrm{mm}$ in diameter, $330 \mathrm{~mm}$ in height), and placed in the $25{ }^{\circ} \mathrm{C}$ constant-temperature water bath. The certain concentration mixed gas was configured by the distribution device. The gas samples were sampled in the intake point and outlet point at regular intervals. When the ratio of gas concentration in the intake point and outlet point was $50 \%$, the adsorption tube was taken and placed into the drying oven at $98-102{ }^{\circ} \mathrm{C}$ for $2 \mathrm{~h}$. The sulfur capacity of WSAC was calculated by the gaining weight. The hydrogen sulfide concentration was $1,400-1,600 \mathrm{mg} / \mathrm{m}^{3}$, the inlet flow was $350 \mathrm{~mL} / \mathrm{min}$ and the air speed was $500 \mathrm{~h}^{-1}$.

\section{Performance characterization of WSAC}

BET, iodine adsorption value, $\mathrm{pH}$ and XPS analysis were used to characterize the WSAC. The iodine adsorption value was measured by the method defined in GB/T 12496.8-1999 [15].

Fig. 1 Experimental device

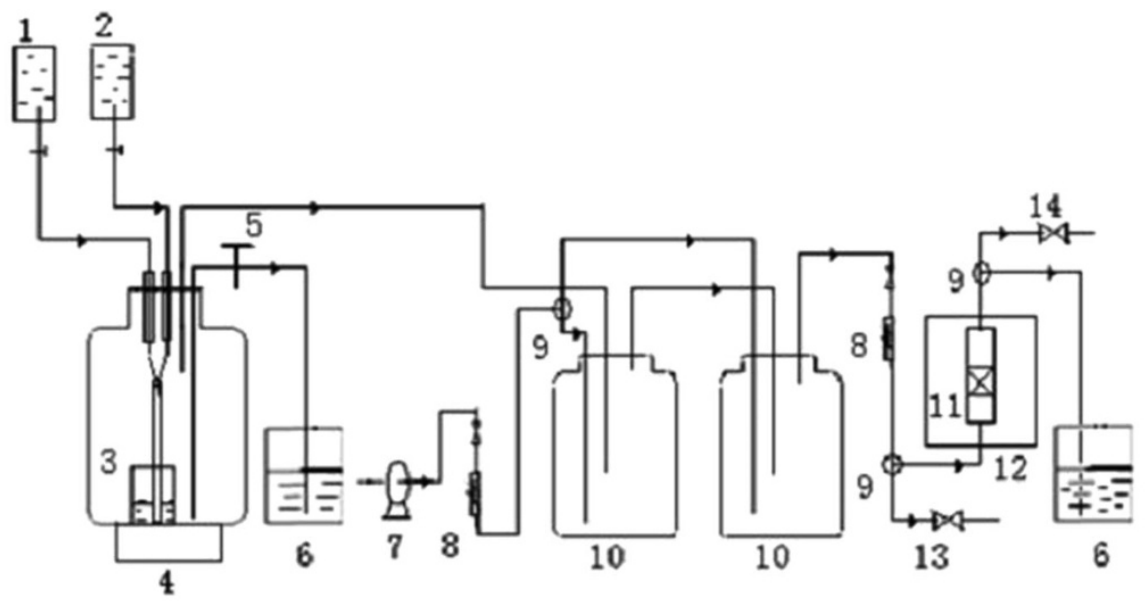

1.Sodium sulfide solution 2.Sulfuric acid solution 3. Beaker 4.Magnetic stirrer 5.valve 6.T ail gas absorber 7.Electromagnetic air compressor 8.Rotameter 9.Triple valve 10.Gas jar 11.Adsorbent tube 12.Constant temperature trough 13.Gas inlet sampling point 14.Gas outlet sampling point 
Modification of WSAC

Modification of activated carbon can effectively increase the sulfur capacity. So, the equivolume immersion method was used for WSAC modification at different $\mathrm{KIO}_{3}$ concentrations. The desulfurization capacity of WSAC was also investigated.

\section{Results and discussion}

Effect of preparation conditions on desulfurization performance of WSAC

\section{Effect of activator mass fraction on desulfurization performance}

In this research, the breakthrough point was defined as the ratio of hydrogen sulphide concentration in the outlet and intake being $10 \%$, the associated time was the breakthrough time. Figure 2 is the breakthrough curve of WSAC adsorbing hydrogen sulphide. The mass fraction of activator $\mathrm{ZnCl}_{2}$ solution was $20,30,40,50$, and $60 \%$, respectively. The ordinate represented the ratio of hydrogen sulfide concentration in outlet point and the intake point.

Figure 2 shows that with the increase of $\mathrm{ZnCl}_{2}$ mass fraction, the breakthrough time increases. When $\mathrm{ZnCl}_{2}$ mass fraction was $60 \%$, the breakthrough time was the longest up to $150 \mathrm{~min}$. $\mathrm{ZnCl}_{2}$ had the strong dehydration and could decrease the carbonization temperature [16]. In addition, $\mathrm{ZnCl}_{2}$ could change the decomposition process, inhibited the tar production, and promoted the pores formation. The pores were likely formed when a large quantity of zinc was removed from the hot carbon matrix (boiling point of zinc chloride is $732{ }^{\circ} \mathrm{C}$ [17]). So, with the increasing $\mathrm{ZnCl}_{2}$ mass fraction, the performance of WSAC also increased. Ozdemir et al. also showed that as the impregnation ratio of $\mathrm{ZnCl}_{2} /$ grape stalk was increased from 0.5 to 2 , the BET surface area of activated carbon prepared increased from 482 to $1,411 \mathrm{~m}^{2} / \mathrm{g}$ [18].

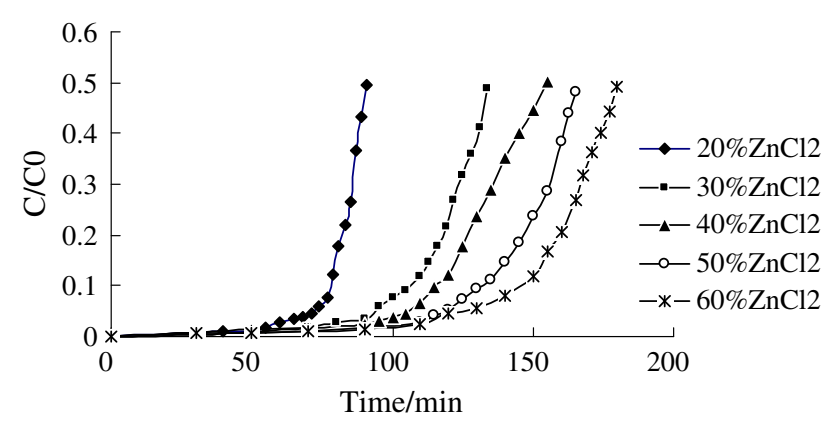

Fig. 2 Breakthrough curve at different $\mathrm{ZnCl}_{2}$ mass fractions
Effect of activation time on desulfurization performance

Figure 3 shows the breakthrough curve of WSAC adsorbing hydrogen sulphide when the activation time is 30, 60, 80 and $100 \mathrm{~min}$, respectively. The breakthrough time first increased and then decreased with the increase of activation time. When the activation time was $80 \mathrm{~min}$, the breakthrough time was the longest. The volatile content in the walnut shell was high. The volatile content must be removed by carbonizing during the preparation of activated carbon. When the activation time was shorter than $80 \mathrm{~min}$, the inadequate carbonization was not conducive to the pore formation. While the activation time was longer than $80 \mathrm{~min}$, the excessive carbonization resulted in the carbon serious loss and pores distortion. So, the short and long activation times are all disadvantages for WSAC adsorbing hydrogen sulphide.

\section{Effect of activation temperature on desulfurization performance}

The activation temperature is a very important parameter which affects the physical characteristics of activated carbon. Figure 4 shows the breakthrough curve of WSAC adsorbing hydrogen sulphide when the activation temperature is $350,450,550$, and $650{ }^{\circ} \mathrm{C}$, respectively. The breakthrough time first increased and then decreased with the increase of activation temperature. When the activation temperature was $450{ }^{\circ} \mathrm{C}$, the breakthrough time was the longest, larger than $150 \mathrm{~min}$. The activation temperature was lower than $700{ }^{\circ} \mathrm{C}$ in Ozdemir et al. [18] research. During the activation process, the action of activator appears in two aspects. On the one hand, activator promotes the pyrolytic reaction and is conducive to the formation of initial pores. On the other hand, the activator is full of pores and it avoids the tar formation. The activated carbon with developed pore structure can be obtained by washing the activator.

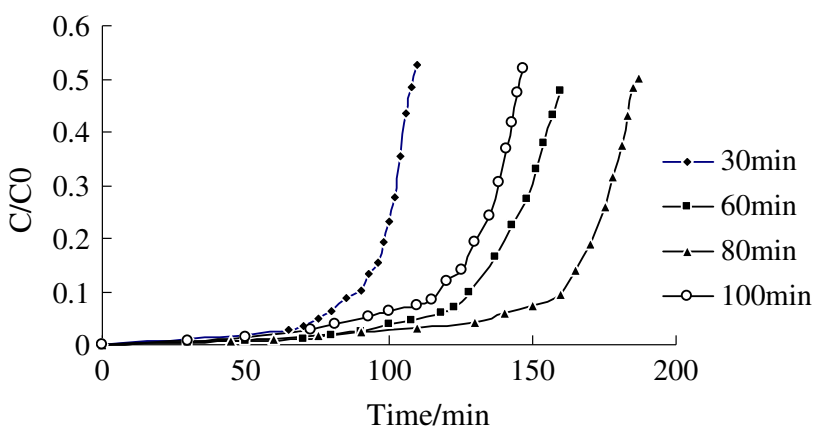

Fig. 3 Breakthrough curve at different activation times

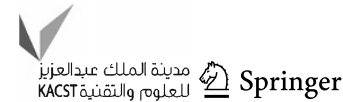




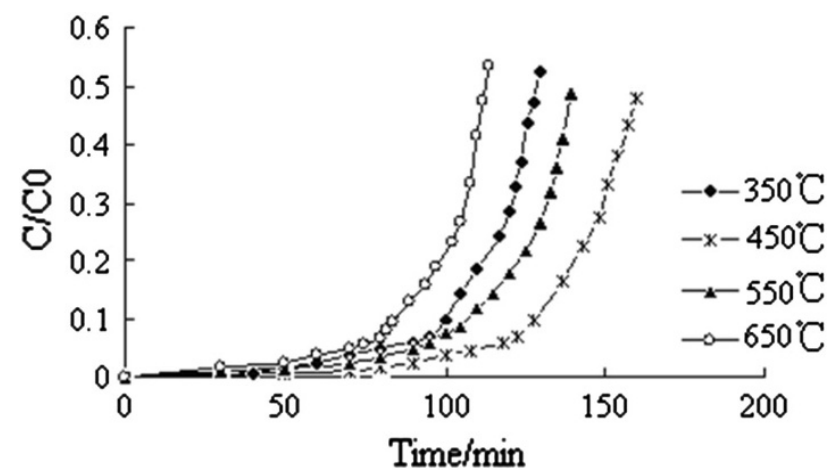

Fig. 4 Breakthrough curve at different activation temperatures

Table 1 Preparation conditions of walnut shell activated carbon

\begin{tabular}{llll}
\hline Factors & $\begin{array}{l}\text { Activator } \\
\text { mass } \\
\text { fraction }(\%)\end{array}$ & $\begin{array}{l}\text { Activation } \\
\text { time }(\mathrm{min})\end{array}$ & $\begin{array}{l}\text { Activation } \\
\text { temperature } \\
\left({ }^{\circ} \mathrm{C}\right)\end{array}$ \\
\hline 1 & 30 & 60 & 350 \\
2 & 40 & 80 & 450 \\
3 & 50 & 100 & 550 \\
\hline
\end{tabular}

Table 2 Orthogonal table of activated carbon preparation experiment

\begin{tabular}{llrll}
\hline Test & $\begin{array}{l}\text { Activator } \\
\text { mass } \\
\text { fraction }(\%)\end{array}$ & $\begin{array}{l}\text { Activation } \\
\text { time }(\mathrm{min})\end{array}$ & $\begin{array}{l}\text { Activation } \\
\text { temperature }\left({ }^{\circ} \mathrm{C}\right)\end{array}$ & $\begin{array}{l}\text { Sulfur } \\
\text { capacity } \\
(\mathrm{mg} / \mathrm{g})\end{array}$ \\
\hline 1 & 30 & 60 & 350 & 113 \\
2 & 30 & 80 & 450 & 198 \\
3 & 30 & 100 & 550 & 167 \\
4 & 40 & 60 & 450 & 351 \\
5 & 40 & 80 & 550 & 304 \\
6 & 40 & 100 & 350 & 248 \\
7 & 50 & 60 & 550 & 316 \\
8 & 50 & 80 & 350 & 290 \\
9 & 50 & 100 & 450 & 273 \\
$\mathrm{k}_{1}$ & 159 & 260 & 217 & \\
$\mathrm{k}_{2}$ & 301 & 229 & 274 & \\
$\mathrm{k}_{3}$ & 293 & 216 & 262 & \\
$\mathrm{R}$ & 142 & 44 & 57 & \\
\hline
\end{tabular}

\section{Preparation conditions optimization of WSAC}

Table 1 lists the preparation factors of WSAC. In order to optimize the preparation conditions of WSAC, the orthogonal array was designed with activator mass fraction, activation time and activation temperature as factors, the sulfur capacity was the index, as shown in Table 2.

Table 2 shows that the sulfur capacity in all test changes considerably. In test 4 , the sulfur capacity was the largest and it was $351 \mathrm{mg} / \mathrm{g}$. The optimal preparation conditions of
WSAC were as follows: the activator mass fraction being $40 \%$, activator time being $60 \mathrm{~min}$, and activation temperature being $450{ }^{\circ} \mathrm{C}$. Under this condition, the breakthrough time was $183 \mathrm{~min}$ and the sulfur capacity was $351 \mathrm{mg} / \mathrm{g}$.

It can be seen that the range of activator mass fraction was the largest (142), while the ranges of activation time and activation temperature are on the same level, which indicated that the activator mass fraction had great influence on sulfur capacity. $\mathrm{ZnCl}_{2}$, as an activating agent, is very efficient to produce activated carbon with high porosity and high surface area and that the mass fraction has a significant influence on porosity development. According to the pore evolution theory, non-carbonic elements such as oxygen and hydrogen during decomposition change to volatiles and a pressure develops inside the particle due to volatiles accumulation. When these trapped volatiles diffuse out through the particle, the pores are evolved [19].

\section{Modification of WSAC}

The impregnation of carbon with transition metals was the well-known way to increase their capacity toward toxic gases [20]. Figure 5 is adsorption desulfurization breakthrough curve of WSAC before and after modification. Comparing with the WSAC before modification, the breakthrough times were all extended after modification. When modifier $\mathrm{KIO}_{3}$ mass concentration was $1 \%$, the breakthrough time was the longest, longer than $400 \mathrm{~min}$. When modifier $\mathrm{KIO}_{3}$ mass concentration was $5 \%$, the breakthrough time was only about $300 \mathrm{~min}$. When modifier $\mathrm{KIO}_{3}$ mass concentration was $0.5 \%$, the breakthrough time was the shortest. This showed that too high and too low modifier $\mathrm{KIO}_{3}$ mass concentration were all disadvantages for modification. If the modifier mass concentration was too low, this led to small active sites on the catalyst surface and low catalytic activation. If the modifier mass concentration was too high, this led to the aggregations of

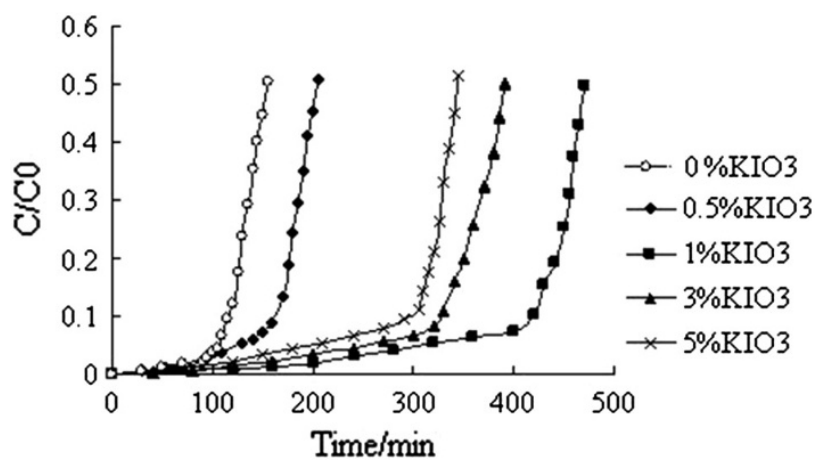

Fig. 5 Adsorption breakthrough curve of modified activated carbon by $\mathrm{KIO}_{3}$ 


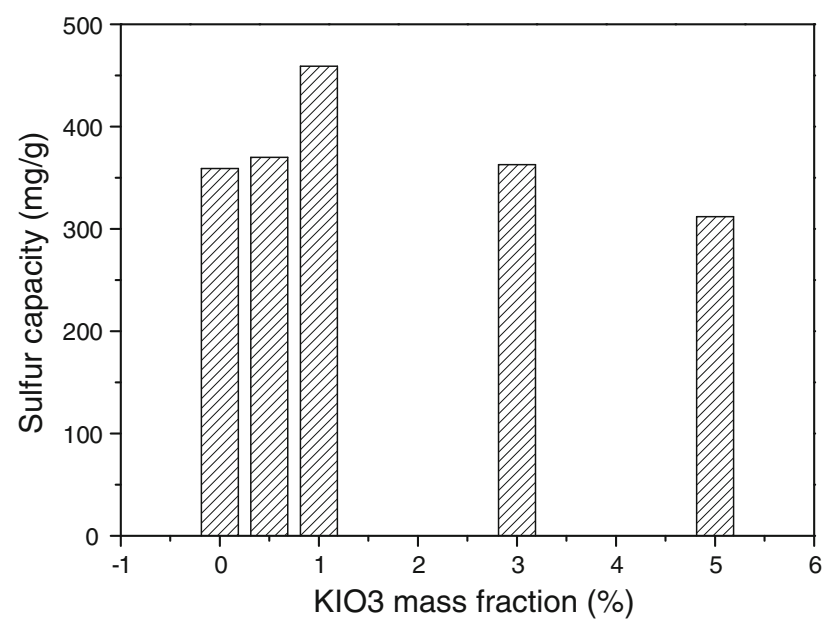

Fig. 6 Modified AC sulfur capacity at different $\mathrm{KIO}_{3}$ mass fractions

Table 3 The pore structure of walnut shell activated carbon sample

\begin{tabular}{lllll}
\hline $\begin{array}{l}\text { Sample } \\
\text { name }\end{array}$ & $\begin{array}{l}\text { Surface } \\
\text { area } \\
\left(\mathrm{m}^{2} / \mathrm{g}\right)\end{array}$ & $\begin{array}{l}\text { Total pore } \\
\text { volume } \\
(\mathrm{mL} / \mathrm{g})\end{array}$ & $\begin{array}{l}\text { Micro pore } \\
\text { volume } \\
(\mathrm{mL} / \mathrm{g})\end{array}$ & $\begin{array}{l}\text { Average } \\
\text { pore size } \\
(\mathrm{nm})\end{array}$ \\
\hline $\begin{array}{c}\text { Walnut } \\
\text { shells AC }\end{array}$ & 2,030 & 1.183 & 0.608 & 1.62 \\
\hline
\end{tabular}

activated centers. In addition, strong oxidization of $\mathrm{KIO}_{3}$ will result in the etching of pore structure and the decrease of catalytic activation.

Figure 6 is the sulfur capacity of WSAC before and after modification at different modifier mass fractions. With $1 \%$ of $\mathrm{KIO}_{3}$, the sulfur capacity of the modified WSAC was the highest, up to $459 \mathrm{mg} / \mathrm{g}$. The sulfur capacities were the same between $\mathrm{KIO}_{3}$ mass fraction of 0.5 and $3 \%$. Sulfur capacity with the $\mathrm{KIO}_{3}$ mass fraction of $5 \%$ was lower than that of before modification. The reason was that strong oxidization of $\mathrm{KIO}_{3}$ could result in the etching of pore structure and the decrease of catalytic activation.

\section{Performance characterization of WSAC}

The BET determination results of WSAC are shown in Table 3 and the physical and chemical properties are shown in Table 4.

Table 3 shows that with the optimum preparation conditions, the specific surface area of WSAC is $2,030 \mathrm{~m}^{2} / \mathrm{g}$. The micropore was developed and the average pore size

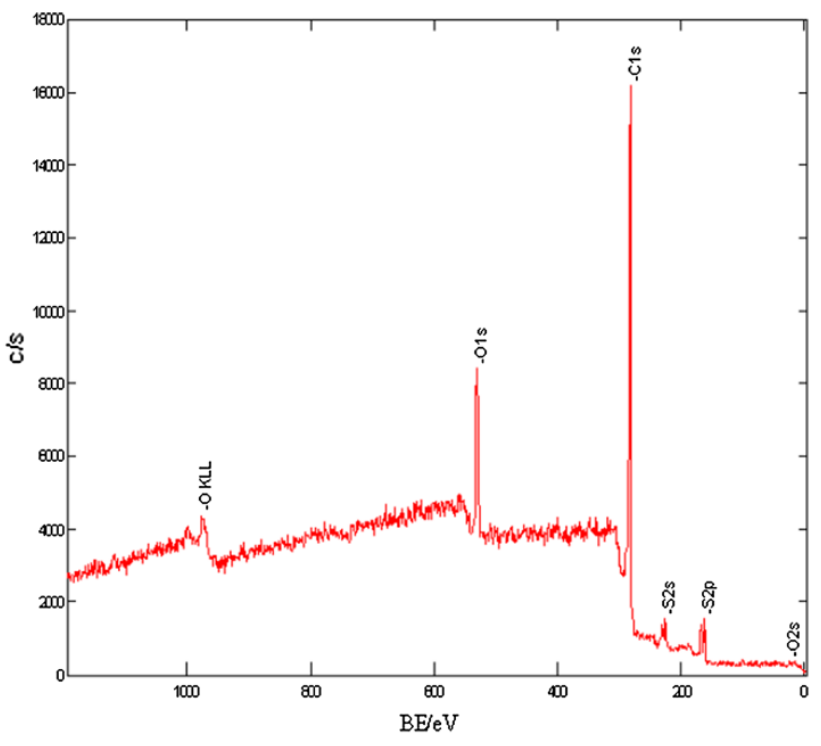

Fig. 7 Full scan of $\mathrm{KIO}_{3}$ modified WSAC after absorption

was small, which was very beneficial for adsorption of hydrogen sulfide gas. The pore structure of WSAC was superior to that of activated carbons in Bashkova et al. research [21]. As indicated previously [22], micropores of activated carbon were considered as activated centers for $\mathrm{H}_{2} \mathrm{~S}$ adsorption/oxidation.

From Table 4 it can be seen that, walnut shell active carbon which was prepared under the optimum process conditions, the iodine adsorption value was the largest (more than 1,000 mg/g) and sulfur capacity was $351 \mathrm{mg} / \mathrm{g}$. It was far higher than the sulfur capacity of commercial activated carbon. It was found that the $\mathrm{pH}$ after adsorption had a decreasing trend by comparing. The change in the $\mathrm{pH}$ after hydrogen sulfide adsorption/oxidation was usually caused by the deposition of $\mathrm{H}_{2} \mathrm{~S}$ oxidation products such as $\mathrm{SO}_{2}$ or $\mathrm{H}_{2} \mathrm{SO}_{4}[23,24]$. A noticeable increase in surface acidity of commercial activated carbon was usually caused by the presence of sulfuric acid. In fact it was found previously that $\mathrm{H}_{2} \mathrm{SO}_{4}$ is the main product of $\mathrm{H}_{2} \mathrm{~S}$ oxidation on virgin carbons and particularly on the wood-based samples [23]. A relatively small decrease in the $\mathrm{pH}$ of the WSAC and $1 \% \mathrm{KIO}_{3}-\mathrm{WSAC}$ in comparison suggested formation of salts and/or elemental sulfur on the surface.

The composition of specific product can be determined by X-ray photoelectron spectroscopy (XPS) characterization methods. The full scan spectra of WSAC after
Table 4 The physical and chemical properties of walnut shell active carbon

\begin{tabular}{|c|c|c|c|c|c|}
\hline Sample name & $\begin{array}{l}\text { Surface area } \\
\left(\mathrm{m}^{2} / \mathrm{g}\right)\end{array}$ & $\begin{array}{l}\text { Sulfur capacity } \\
(\mathrm{mg} / \mathrm{g})\end{array}$ & $\begin{array}{l}\text { Iodine value } \\
(\mathrm{mg} / \mathrm{g})\end{array}$ & $\begin{array}{l}\mathrm{pH} \text { before } \\
\text { adsorption }\end{array}$ & $\begin{array}{l}\mathrm{pH} \text { after } \\
\text { adsorption }\end{array}$ \\
\hline WSAC & 2,030 & 351 & $1,023.4$ & 5.96 & 5.88 \\
\hline $1 \% \mathrm{KIO}_{3}-\mathrm{WSAC}$ & 1 & 459 & 813.9 & 5.61 & 3.82 \\
\hline Commercial AC & 800 & 46 & 606.6 & 9.13 & 6.19 \\
\hline
\end{tabular}


adsorption which was modified by potassium iodate change is shown in Fig. 7.

Figure 7 shows that the strongest peak is the C1s peak, followed by O1s peaks, O KLL peak, S2s peak, and S2p peak. The presence of the peaks explained the main reason for catalyst deactivation after adsorption. The carbon deposits formed on the surface and elemental sulfur product blocked the WSAC pores.

\section{Conclusion}

1. The optimal process conditions of WSAC were the activator mass fraction being $40 \%$, activation time being $80 \mathrm{~min}$, and activation temperature being $450{ }^{\circ} \mathrm{C}$. Under this condition, the breakthrough time was $183 \mathrm{~min}$ and the sulfur capacity was $351 \mathrm{mg} / \mathrm{g}$.

2. $1 \%$ of potassium iodate modification was the best, the sulfur capacity can be increased to $459 \mathrm{mg} / \mathrm{g}$, and breakthrough time was up to $400 \mathrm{~min}$.

3. The specific surface area of WSAC was $2,030 \mathrm{~m}^{2} / \mathrm{g}$, the average pore size was $1.62 \mathrm{~nm}$, micropore was developed, and it was very beneficial for adsorption of hydrogen sulphide.

4. By modified with $1 \%$ potassium iodate, $\mathrm{pH}$ of WSAC was lower. It can be concluded that acidic substances were generated or part of hydrogen sulfide was trapped by physical adsorption.

Open Access This article is distributed under the terms of the Creative Commons Attribution License which permits any use, distribution, and reproduction in any medium, provided the original author(s) and the source are credited.

\section{References}

1. Qu M (2008) Odor pollution sources and treatment technology of domestic oil refineries. Petrochem Saf Environ Prot Technol 24(4):47-50

2. Kawase M, Otaka M (2013) Removal of $\mathrm{H}_{2} \mathrm{~S}$ using molten carbonate at high temperature. Waste Manag 33:2706-2712

3. Nowicki P, Skibiszewska P, Pietrzak R (2014) Hydrogen sulphide removal on carbonaceous adsorbents prepared from coffee industry waste materials. Chem Eng J 248:208-215

4. Perraud I, Ayral RM, Cammarano C, Rouessac F, Hulea V, Ayral A (2014) Sulfidation and sulfur capacity of fine $\mathrm{ZnO}$ powder derived from thermal oxidation of mechanosynthesized $\mathrm{ZnS}$ powder. Chem Eng J 241:360-365

5. Ramirez M, Fernandez M, Granada C, Le Borgene S, Gomez JM, Cantero D (2011) Biofiltration of reduced sulphur compounds and community analysis of sulphur-oxidizing bacteria. Bioresour Technol 102:4047-4053
6. Ministry of Environmental Protection of the People's Republic of China (1994) Odorous pollutant discharge standard (GB 14554-1993)

7. Kroschwitz JI, Howe-Grant M (1996) Encyclopedia of chemical technology. Wiley

8. Cheremisinoff PN (1993) Air pollution control and design for industry. Marcel Dekker Inc, New York

9. Xiao YH, Wang SD, WU DY, Yuan Q (2008) Catalytic oxidation of hydrogen sulfide over unmodified and impregnated activated carbon. Sep Purif Technol 59:326-332

10. Musialik-piotrowska A, Mendyka B (2004) Catalytic oxidation of chlorinated hydrocarbons in two-component mixtures with selected VOCs. Catal Today 90:139-144

11. Alvarez-Galvan MC, de la Pena O'Shea VA, Fierro JLG, Arias PL (2003) Alumina supported manganese- and manganese-palladium oxide catalysts for VOCs combustion. Catal Commun 4(5):223-228

12. van den Brikn RW, Louw R, Mulder P (1998) Formation of polychlorinated benzenes during the catalytic combustion of chlorobenzene using a $\mathrm{Pt} / \gamma-\mathrm{Al}_{2} \mathrm{O}_{3}$ catalyst. Appl Catal B 16(3):219-226

13. Fang HB, Zhao JT, Fang YT, Huang JJ, Wang Y (2013) Selective oxidation of hydrogen sulfide to sulfur over activated carbonsupported metal oxides. Fuel 108:143-148

14. Chen J, Xie ZM (2013) Removal of $\mathrm{H}_{2} \mathrm{~S}$ in a novel dielectric barrier discharge reactor with photocatalytic electrode and activated carbon fiber. J Hazard Mater 261(15):38-43

15. (1999) China State Bureau of Quality and Technical Supervision, test methods of wooden activated carbon-determination of iodine number, GB/T 12496.8-1999

16. Tsai WT, Chang CY, Lee SL (1998) A low cost adsorbent from agricultural waste corn cob by zinc chloride activation. Bioresour Technol 64(3):211-217

17. Weast RC, Melvin JA (1981) Handbook of chemistry and physics. CRC Press, Boca Raton

18. Ozdemir I, Sahin M, Orhan R, Erdema M (2014) Preparation and characterization of activated carbon from grape stalk by zinc chloride activation. Fuel Process Technol 125:200-206

19. Raveendran K, Ganesh A (1997) Adsorption characteristics and pore development of biomass-pyrolysis char. Fuel 77:769-781

20. Alder JF, Fielden PR, Smith SJ (1998) The adsorption of hydrogen cyanide by impregnated activated carbon cloth. Part II. Reactivity of impregnated metal carboxylates towards hydrogen cyanide. Carbon 26(5):713-721

21. Bashkova S, Baker FS, Wu XX, Armstrong TR, Schwartz V (2007) Activated carbon catalyst for selective oxidation of hydrogen sulphide: on the influence of pore structure, surface characteristics, and catalytically-active nitrogen. Carbon 45:1354-1363

22. Bandosz TJ (2002) On the adsorption/oxidation of hydrogen sulfide on unmodified activated carbon at temperatures near ambient. J Colloid Interface Sci 246(1):1-20

23. Adib F, Bagreev A, Bandosz TJ (2000) Analysis of the relationship between $\mathrm{H}_{2} \mathrm{~S}$ removal capacity and surface properties of unmodified activated carbons. Environ Sci Technol 34(4):686-692

24. Adib F, Bagreev A, Bandosz TJ (1999) Effect of pH and surface chemistry on the mechanism of $\mathrm{H}_{2} \mathrm{~S}$ removal by activated carbons. J Colloid Interface Sci 216(2):360-369 